tumors in head and neck cancer: A systematic review, Head Neck, 42(3), 456-466.

5. Nguyển Văn Đăng Luận văn chuyên khoa II Đánh giá kết quả hóa xạ trị ung thư biểu mô vảy vùng đâu cổ - thức quản tai bênh viên $K$. .

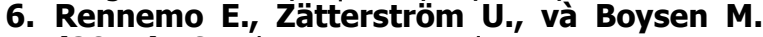
(2011). Synchronous second primary tumors in 2,016 head and neck cancer patients: role of symptom-directed panendoscopy. Laryngoscope, 121(2), 304-309.
7. Rennemo E., Zätterström U., và Boysen M. (2008). Impact of second primary tumors on survival in head and neck cancer: an analysis of 2,063 cases. Laryngoscope, 118(8), 1350-1356.

8. Bertolini F., Trudu L., Banchelli F. và cộng sứ. (2021). Second primary tumors in head and neck cancer patients: The importance of a "tailored" surveillance. Oral Dis, 27(6), 1412-1420.

\title{
PHÂN TÍCH CHI PHÍ ĐÎ̀U TRI HEN PHẾ QUẢN CỦA NGƯờI BÊNH THAM GIA CHƯO'NG TRÌNH QUẢN LÝ HEN NGOAI TRÚ TẠI BỆNH VIỆN QUẬN 11 TRÊN QUAN ĐIỂM NGƯỜI CHI TRẢ
}

\section{TÓM TẮT}

Hen phế quản (HPQ) với tính chất mạn tính có thời gian điều trị kéo dài và nhiều biến chứng nặng nề là gánh nặng kinh tế tương đối lớn cho người bệnh (NB), gia đình và xã hội. Đơn vị quản lý hen và COPD ngoại trú (ACOCU) áp dụng tại bệnh viện Quận 11 từ năm 2017 đã được chứng minh nâng cao hiệu quả kiểm soát tình trạng bệnh lý. Tuy nhiên chưa có nghiên cứu nào đánh giá lợi ích của chương trình quản lý hen ngoại trú (QLHNT) ở khía cạnh chi phí, đặc biệt trên NB HPQ. Vì vậy nghiên cứu được thực hiện nhằm mục tiêu đánh giá sự thay đổi về chi phí điêu trị HPQ qua hai năm NB tham gia chương trình QLHNT tai bênh viện Quận 11. Nghiên cứu mô tả cắt ngang chi phí điều trị dưa trên dữ liêuu hồi cứu hồ sơ bênh án và dữ liệu thanh toán khám chữa bệnh của NB HPQ từ 16 tuổi trở lên tham gia khám, điều trị liên tục hai năm tại bệnh viện Quận 11 trong giai đoạn 2017-2020 (đối với chi phí trực tiếp y tế); và dựa trển phỏng vấn trực tiếp NB đến điều trị hen suyễn ngoại trú tại bệnh viện Quận 11 từ tháng 02/2021 đến tháng 05/2021 (đối với chi phí trực tiếp ngoài y tế và gián tiếp). Tất cả chi phí thu thập được sẽ được quy đổi về năm 2020 sử dụng chỉ số giá tiêu dùng (CPI). Khảo sát mấu nghiên cứu gồm 232 NB cho dữ liệu hồi cứu và 159 NB cho dữ liệu phỏng vấn, nghiên cứu ghi nhận sự khác biệt có ý nghĩa thống kê trong tổng chi phí điều trị HPQ trung bình trên một NB ở năm thứ nhất (8.066.051 VNĐ; 95\% KTC: 7.338.823 - 8.793.279 VNĐ) so với năm thứ hai (6.324.916 VND; 95\% KTC: 5.638.181 7.011.651 VNĐ) với $p<0,05$. Trong cấu trúc tổng chi phí, chi phí trực tiếp y tế chiếm tỷ lệ cao nhất và dao

${ }^{1}$ Dai hoc Y Dươ TP HCM

${ }^{2}$ Trường Đại học Nguyễn Tất Thành

33ệnh viện Quận 11

Chịu trách nhiệm chính: Nguyễn Thị Thu Thủy

Email: nguyenthuthuy@ump.edu.vn

Ngày nhận bài: 6.9.2021

Ngày phản biên khoa họ: 27.10.2021

Ngày duyệt bài: 8.11.2021

\section{Nguyễn Thị Xuân Liễu ${ }^{2}$, Lê Đỗ Thành Đạt ${ }^{1}$, Phạm Quốc Dũng ${ }^{3}$, Nguyễn Thị Thu Thủy ${ }^{1}$}

động từ $67,41 \%$ đến $73,84 \%$; trong đó chi phí thuốc luôn dần đầu (79\%).

Tư khóa: hen phế quản, chi phí trực tiếp y tế, bệnh viện Quận 11.

\section{SUMMARY}

\section{ANALYSIS OF COST IN THE TREATMENT OF BRONCHIAL ASTHMA OF ACOCU PATTERNS PARTICIPANTS FOR 2017 -2020 AT} DISTRICT 11 HOSPITAL

Asthma with chronic characteristics and many serious complications has become relatively large economic burden for patients, family and society. Asthma COPD outpatient care unit (ACOCU) has applied at District 11 hospital since 2017 and has been proved to improve the efficacy of disease management. However, until now no available study on the benefit of outpatient asthma management program (OAMP) in treatment cost. The aim of this study is to evaluate the treatment costs of asthma of patients over two years participating in OAMP at District 11 hospital. A cross-sectional descriptive study of treatment costs based on retrospective data retrieved from medical records and payment data for asthma treatment patients aged 16 years and older participating in OAMP for two years at District 11 hospital in the period 2017-2020 (for direct medical cost); based on direct interviews with asthma patients, treated at District 11 hospital from February 2021 to May 2021 (for indirect and direct nonmedical cost). All costs have been converted in 2020 using Consumer Price Index (CPI). With sample of 232 patients for retrospective data and 159 patients for interview data, the study recorded a statistically significant difference in the mean asthma of a patient in the first year (8.066.051 VND; 95\% CI: 7.338.823 - 8.793.279 VNĐ) compared with the second year (6.324.916 VND; 95\% CI: 5.638.181 - 7.011.651 VND) with $\mathrm{p}<$ 0.05. Out of total costs, direct medical costs accounted for the highest proportion and range from $67.41 \%$ to $73.84 \%$; in which drug costs were always highest (79\%). 
Keywords: asthma, direct medical costs, District 11 hospital

\section{I. ĐặT VẤN ĐỀ}

Ngày nay trên thế giới các bệnh không lây nhiễm là nguyên nhân chính cho hơn $70 \%$ tổng sỗ ca tử vong trên toàn thế giới, trong đó có hen phế quản (HPQ). Tỉ lệ mắc bệnh $\mathrm{HPQ}$ ngày càng gia tăng ở các nước với đủ mọi lứa tuổi. Tổ Chức Y Tế Thế Giới (World Health Organization WHO) ước tính có khoảng 300 triệu người mắc HPQ năm 2005 và dự đoán sẽ tăng lên khoảng 400 triệu người vào năm 2025 [1].

HPQ là bệnh mạn tính với thời gian điều trị kéo dài và nhiều biến chứng nặng nề. Chi phí cho mỗi người bệnh $\mathrm{HPQ}$ hàng nằm lên tới 3.300 USD và các chi phí y tễ liên quan đến HPQ tăng dần từ 48,6 tỷ USD (năm 2002) lên 50,1 tỷ USD (năm 2007) [2]. Chi phí (CP) trực tiếp và gián tiếp cho điêu trị HPQ tại Mỹ hớn 14,5 tỉ USD, chiếm 1\% ngân sách cho y tế [3]. Tại Ẫn Độ chi phí cho điều trị HPQ chiếm khoảng $9 \%$ tổng thu nhập bình quân đầu người [4]. Chi tiêu từ ngân sách cho bệnh $\mathrm{HPQ}$ tại Úc vào năm 2004 khoảng 606 triệu USD tương ứng 1,2\% tổng phân bổ chi tiêu chăm sóc sức khỏe [5]. Có thể thây $\mathrm{HPQ}$ thật sự đem lại gánh nặng kinh tế tương đôi lớn cho người bệnh (NB), gia đình và xã hội.

Quản lý người bệnh $\mathrm{HPQ}$ là giải pháp quan trong nhằm nâng cao hiệu quả điều trị và giảm bớt gánh nặng kinh tế của bệnh. Đơn vị quản lý hen và COPD ngoại trú (ACOCU - Asthma COPD outpatient care unit) được thành lập tại bệnh viện Quận 11 từ năm 2017 đã được chứng minh nẩng cao hiệu quả kiểm soát tình trạng bệnh lý [5]. Tuy nhiển chưa có nghiên cứu nào đánh giá lợi ích của chương trình ở khía cạnh chi phí. Vì vậy nghiên cứu được thực hiện nhằm mục tiêu đánh giá sự thay đổi về chi phí điều trị HPQ qua hai năm NB tham gia chương trình quản lý hen ngoại trú (QLHNT) tại bệnh viện Quận 11. Từ đó cũng góp phần nhận định về chương trình QLHNT đang triển khai tại bệnh viện Quận 11.

\section{II. ĐỐI TƯỢNG VÀ PHƯƠNG PHÁP NGHIÊN CỨU 2.1 Đối tượng nghiên cứu:}

- Hồ sơ bệnh án của người bệnh HPQ được điều trị tại bệnh viện Quận 11.

- Dữ liệu điện tử về thanh toán dịch vụ khám và điều trị của người bệnh HPQ tại bệnh viện Quận 11.

- Người bệnh HPQ tham gia khám và điều trị tại bệnh viện Quận 11 từ tháng 02/2021 đến tháng 05/2021.

2.2 Phương pháp nghiên cứu. Nghiên cứu mô tả cắt ngang dựa trên dữ liệu hồi cứu hồ sơ bệnh án, dữ liệu điện tử về chi phí điều trị của người bệnh HPQ được lưu trữ tại bênh viện Quận 11 trong giai đoạn 2017 - 2020; phỏng vấn trực tiếp người bệnh thăm khám và điều trị $\mathrm{HPQ}$ tại bệnh viện Quận 11 từ tháng 02/2021 đến tháng 05/2021 bằng phiếu phỏng vấn.

Mẫu nghiên cứu. Cõ̃ mẫu nghiên cứu

a) Cõ̃ mẫu 1 (đối với CP trực tiếp y tế): tất cả các người bệnh $\mathrm{HPQ}$ thỏa tiêu chí chọn mẫu

Tiêu chuẩn lựa chọn

- NB được chẩn đoán $\mathrm{HPQ}$;

- Độ tuổi từ đủ 16 tuổi trở lên;

- Bắt đầu tham gia khám và điều trị $\mathrm{HPQ}$ tại bệnh viện Quận 11 trong giai đoạn 2017 - 2020;

- Có ít nhất 2 năm tham gia khám và điều trị liên tục tại bệnh viện Quận 11

- Có bệnh án được lưu trữ tại bệnh viện Quận 11.

Tiêu chuấn loại trừ

- Quá trình điều trị gián đoạn do không tuân thủ điều trị

- Hồ sơ bệnh án thiếu các thông tin cần thiết cho nghiên cứu;

- Không đầy đủ dữ liệu về thanh toán khám chữa bệnh.

b) Cỡ mẫu 2 (đối với CP trực tiếp ngoài y tế và gián tiếp) được xác định dựa trên cỡ mẫu NB điêu trị 2 năm liên tục (mục a) theo công thức [6]:

$$
n=\frac{N}{1+N \cdot e^{2}}=\frac{232}{1+232 \cdot 0,05^{2}}=147
$$

Trong đó: N: tổng số người bệnh điều trị 2 năm liên tục (232)

n: cõ̃ mẫu nghiên cứu tối thiểu

e: sai số cho phép $(e=0,05)$

Như vậy cõ mẫu tối thiểu cần cho khảo sát là 147 người bệnh. Người bệnh được lựa chọn theo tiêu chí chọn mẫu sau đây:

\section{Tiêu chuẩn lưa chon}

- NB nằm trong danh sách được lựa chọn cho cõ mẫu 1

- NB đồng ý tham gia nghiên cứu.

\section{Tiêu chuấn loai trừ}

- NB không cung cấp đầy đủ thông tin trong phiếu khảo sát;

- NB rối loạn về ngôn ngữ hoặc khả năng nhận thức;

Biến số nghiên cứu. Chi phí trung bình hàng năm của người bệnh $\mathrm{HPQ}$ bao gồm $\mathrm{CP}$ trực tiếp y tế (TTYT), CP trực tiếp ngoài y tế (TT $\mathrm{NYT}$ ) và $\mathrm{CP}$ gián tiếp (GT) [7]. Để đảm bảo sự đồng nhất về giá trị, các chi phí trực tiếp y tế được quy đổi giá trị về năm 2020 dựa trên chỉ số giá tiêu dùng (Consumer Price Index- CPI) theo 
công thức sau:

$$
C P_{2020}=C P_{Q K} \times \frac{C P I_{2020}}{C P I_{Q K}}
$$

Trong đó: $\mathrm{CP}_{2020}$ - Chi phí quy đổi năm 2020 $\mathrm{CP}_{\mathrm{QK}}-\mathrm{Chi}$ phí năm phát sinh trong quá khứ CPI 2020 - Chỉ số giá tiêu dùng năm 2020

CPIQK - Chỉ số giá tiêu dùng năm phát sinh chi phí trong quá khứ

Thống kê và xử lý số liệu. Các số liệu được xử lý và phân tích bằng phần mềm Microsoft Excel 2016, Microsoft SPSS 20.0 với các phép kiểm thống kê phù hợp và độ tin cậy $95 \%$.

\section{KẾT QUẢ NGHIÊN CỨU}

3.1 Đặc điểm người bệnh. Khảo sát mẫu nghiên cứu gồm 232 NB tại bệnh viện Quận 11, ghi nhận đặc điểm chung trình bày trong Bảng 1 .

Bảng 1. Đặc điểm chung của người bệnh hen

\begin{tabular}{|c|c|c|c|}
\hline \multirow{2}{*}{ Đặc điểm } & $\begin{array}{c}\text { Phấn } \\
\text { nhóm }\end{array}$ & $\begin{array}{c}\text { Số người } \\
\text { bệnh }\end{array}$ & Tỷ lệ \% \\
\hline \multirow{2}{*}{ Giới tính } & Nam & 86 & 37,07 \\
\cline { 2 - 4 } & Nữ & 146 & 62,93 \\
\hline
\end{tabular}

\begin{tabular}{|c|c|c|c|}
\hline \multirow{2}{*}{$\begin{array}{c}\text { Khu vực } \\
\text { sống }\end{array}$} & Tp HCM & 222 & 95,69 \\
\cline { 2 - 4 } & Tỉnh & 10 & 4,31 \\
\hline \multirow{2}{*}{$\begin{array}{c}\text { Mức thanh } \\
\text { toán BHYT }\end{array}$} & $100 \%$ & 32 & 13,79 \\
\cline { 2 - 4 } & $95 \%$ & 13 & 5,60 \\
\cline { 2 - 4 } & $80 \%$ & 187 & 80,61 \\
\hline \multirow{2}{*}{$\begin{array}{c}\text { Giá trị } \\
\text { trung bình }\end{array}$} & $\begin{array}{c}\text { Độ lệch } \\
\text { chuẩn }\end{array}$ & $\begin{array}{c}\text { Giá trị nhỏ } \\
\text { nhất - Giá } \\
\text { trị lớn nhất }\end{array}$ \\
\hline Tuối & 57,17 & 15,03 & $17-91$ \\
\hline
\end{tabular}

Ghi chú: Tp HCM - thành phố Hồ Chí Minh, BHYT - bảo hiểm y tế

Theo bảng 1 , nghiên cứu ghi nhận tỷ lệ NB nam: nữ là $1: 1,7$ với độ tuổi trung bình $57,17 \pm 15,03$ và dao động từ 17 đến 91 tuổi. Đa phần NB sinh sống tại tp.HCM với $95,69 \%$ và mức thanh toán bảo hiểm y tế chủ yếu là $80 \%$ (chiếm 80,61\%).

Chi phí trực tiếp y tế. Khảo sát mẫu nghiên cứu gồm 232 NB tại bệnh viện Quận 11, nghiên cứu ghi nhận chi phí trực tiếp y tế trong điêu trị HPQ năm đầu tiên và năm thứ hai tham gia chương trình QLHNT và trình bày trong Bảng 2.

Bảng 2.9 Chi phí trực tiếp y tế trong điều trị HPQ hai năm tham gia chương trình QLHNT (đơn vị tính: VNĐ, quy đổi về năm 2020)

\begin{tabular}{|c|c|c|c|c|c|c|c|c|}
\hline & \multicolumn{3}{|c|}{ Năm 1} & & \multicolumn{4}{|c|}{ Năm 2} \\
\hline $\begin{array}{l}\text { Chi } \\
\text { phí }\end{array}$ & $\begin{array}{l}\text { Trung bình } \\
\text { (95\% KTC) }\end{array}$ & $\begin{array}{c}\text { Trung vị } \\
\text { (KTPV) }\end{array}$ & $\begin{array}{l}\text { Min - } \\
\max \end{array}$ & $\begin{array}{c}\text { Tỷ lệ } \\
\%\end{array}$ & $\begin{array}{l}\text { Trung bình } \\
\text { (95\% KTC) }\end{array}$ & $\begin{array}{c}\text { Trung vị } \\
\text { (KTPV) }\end{array}$ & Min - max & $\begin{array}{c}\text { Tỷ lệ } \\
\%\end{array}$ \\
\hline $\begin{array}{l}\text { CP } \\
\text { khám } \\
\text { bệnh }\end{array}$ & $\begin{array}{c}343.078 \\
(312.724- \\
373.431)\end{array}$ & $\begin{array}{c}314.816 \\
(146.071- \\
499.113)\end{array}$ & \begin{tabular}{|c|}
$28.784-$ \\
1.001 .287
\end{tabular} & 6,31 & $\begin{array}{c}280.477 \\
(253.793- \\
307.161)\end{array}$ & $\begin{array}{c}241.045 \\
(106.834- \\
404.638)\end{array}$ & $\begin{array}{l}27.780- \\
817.511\end{array}$ & 6,01 \\
\hline $\begin{array}{l}\text { CP } \\
\text { thuốc }\end{array}$ & $\begin{array}{c}4.313 .449 \\
(3.899 .214- \\
4.727 .684)\end{array}$ & \begin{tabular}{|c|}
3.611 .556 \\
$(1.955 .918-$ \\
$6.155 .308)$
\end{tabular} & \begin{tabular}{|c|}
$99.215-$ \\
19.159 .795
\end{tabular} & 79,34 & $\begin{array}{c}3.672 .455 \\
(3.309 .179- \\
4.035730)\end{array}$ & \begin{tabular}{|c|}
3.150 .461 \\
$(1.318 .102-$ \\
$5.217 .479)$
\end{tabular} & $\begin{array}{c}78.839- \\
14.742 .404\end{array}$ & 78,64 \\
\hline $\begin{array}{l}\text { CP xét } \\
\text { nghiêem, } \\
\text { chẩn } \\
\text { đoán }\end{array}$ & $\begin{array}{c}524.318 \\
(456.078- \\
592.599)\end{array}$ & $\begin{array}{c}372.541 \\
(190.429- \\
729.636)\end{array}$ & $\begin{array}{c}0- \\
3.825 .573\end{array}$ & 9,64 & $\begin{array}{c}465.803 \\
(392.099- \\
539.507)\end{array}$ & $\begin{array}{c}278.000 \\
(127.828- \\
593.190)\end{array}$ & $\begin{array}{c}0- \\
3.459 .557\end{array}$ & 9,97 \\
\hline $\begin{array}{l}\text { CP vât } \\
\text { tư y tế }\end{array}$ & $\begin{array}{c}1.705 \\
(19-3.392)\end{array}$ & 0 & $|0-181.038|$ & 0,03 & $\begin{array}{l}4.820 \\
(2.215- \\
7.425)\end{array}$ & 0 & $\begin{array}{c}0- \\
178.922\end{array}$ & 0,10 \\
\hline $\begin{array}{l}\text { CP thú } \\
\text { thuâât, } \\
\text { phẫu } \\
\text { thuật }\end{array}$ & $\begin{array}{c}82.107 \\
(52.297- \\
111.917)\end{array}$ & 0 & $\begin{array}{c}0- \\
1.674 .364\end{array}$ & 1,51 & $\begin{array}{c}74.439 \\
(44.844- \\
104.032)\end{array}$ & 0 & $\begin{array}{c}0- \\
1.831 .968\end{array}$ & 1,59 \\
\hline $\begin{array}{l}\text { CP ngày } \\
\text { giường }\end{array}$ & $\begin{array}{c}172.106 \\
(94.005- \\
250.208)\end{array}$ & 0 & $\left|\begin{array}{c}0- \\
4.937 .222\end{array}\right|$ & 3,17 & $\begin{array}{l}171.951 \\
(96.416- \\
247.484)\end{array}$ & 0 & $\begin{array}{c}0- \\
4.486 .401\end{array}$ & 3,69 \\
\hline $\begin{array}{l}\text { CP trực } \\
\text { tiếp y tế }\end{array}$ & $\begin{array}{c}5.436 .764 \\
(4.928 .144- \\
5.945 .384)\end{array}$ & $\begin{array}{l}4.639 .686 \\
(2.562 .862- \\
7.453 .851)\end{array}$ & \begin{tabular}{|c|}
$235.008-$ \\
20.438 .26 \\
5
\end{tabular} & 100 & $\begin{array}{c}4.669 .945 \\
(4.180 .437- \\
5.159 .452)\end{array}$ & \begin{tabular}{|c|}
3.982 .435 \\
$(1.749 .001-$ \\
$6.453 .526)$
\end{tabular} & $\begin{array}{c}110.322- \\
25.370 .190\end{array}$ & 100 \\
\hline P-value & & & & & & & & \\
\hline
\end{tabular}

Ghi chú: CP - Chi phí; KTC - khoảng tin cậy; KTPV - khoảng tứ phân vị

Theo bảng 2, chi phí trực tiếp y tế trên NB $\mathrm{HPQ}$ cho năm đầu tham gia điều trị tại bệnh viện Quận 11 có giá trị trung bình 5.436.764 VNĐ
(95\% KTC: 954.928.144 - 5.945.384 VND). Trong đó chi phí thuốc có giá trị trung bình cao nhất (4.313.449 VNĐ; 95\% KTC: $3.899 .214-$ 
4.727.684 VNĐ), chi phí vật tư y tế có giá trị trung bình thấp nhất (1.705 VNĐ; 95\% KTC: 19 - 3.392 VND). Chi phí trực tiếp y tế trung bình trên mỗi NB HPQ cho năm thứ hai giảm còn 4.669.945 VND (95\% KTC: 4.180.437 5.159.452 VNĐ). Trong đó chi phí thuốc có giá trị cao nhất 3.672.455 VND (95\% KTC: 3.309.179 - 4.035730 VND) và thấp nhất là chi phí vật tư y tế với 4.820 VNĐ (95\% KTC: 2.215 $7.425 \mathrm{VN \Xi )}$ ). Ở cả 2 năm điều trị, mặc dù giá trị khác nhau, cấu trúc chi phí TTYT là tương đồng nhau với tỷ lệ cao nhất dành cho thuốc $(78,6$ -
$79,3 \%$ ), tiếp theo dành cho $\mathrm{CP}$ xét nghiệm chẩn đoạn $(9,6-10,0 \%)$ và tỷ lệ thấp nhất dành cho $\mathrm{CP}$ vật tư y tế (không quá $0,1 \%$ ). Các $\mathrm{CP}$ khác bao gồm CP khám bệnh, ngày giường, thủ thuật đều giảm nhe và chỉ có mỗi chi phí vật tư $y$ tế là tăng nhưng do chi phí này không đáng kể nên không làm tăng chi phí trực tiếp y tế.

Chi phí trực tiếp ngoài y tế. Phỏng vấn mẫu nghiên cứu gồm 159 NB tại bệnh viện Quận 11 từ tháng 02/2021 đến tháng 05/2021, nghiên cứu ghi nhận chi phí trực tiếp ngoài y tế (CP TT NYT) và trình bày tại Bảng 3.

Bảng 3. Chi phí trực tiếp ngoài y tế của mối người HPQ (đơn vị tính: VNĐ)

\begin{tabular}{|c|c|c|c|c|c|}
\hline \multicolumn{2}{|c|}{ Chi phí } & $\begin{array}{l}\text { Trung bình - } \\
\text { (95\% KTC) }\end{array}$ & Tỷ lệ \% & $\begin{array}{l}\text { Trung vị } \\
\text { (KTPV) }\end{array}$ & $\begin{array}{l}\text { Min - } \\
\max \end{array}$ \\
\hline \multirow{5}{*}{$\begin{array}{l}\text { Mỗi đợt } \\
\text { khám } \\
\text { ngoaai } \\
\text { trú }\end{array}$} & CP ăn uống & $\begin{array}{c}4.420 \\
(2.427-6.413)\end{array}$ & 2,69 & 0 & $0-50.000$ \\
\hline & $\begin{array}{l}\text { CP vâan } \\
\text { chuyển }\end{array}$ & $\begin{array}{c}18.349 \\
(13.840-22.857)\end{array}$ & 11,19 & $\begin{array}{c}12.878 \\
(10.822-16.476) \\
\end{array}$ & $\begin{array}{c}0- \\
200.000 \\
\end{array}$ \\
\hline & CP ở trọ & 0 & 0 & 0 & 0 \\
\hline & CP khác & $\begin{array}{c}141.087 \\
(59.675-222.499)\end{array}$ & 86,12 & 0 & $\begin{array}{c}0- \\
3.600 .000\end{array}$ \\
\hline & $\begin{array}{c}\text { Tống CP TT } \\
\text { NYT }\end{array}$ & $\begin{array}{c}163.856 \\
(81.943-245.768)\end{array}$ & 100 & $\begin{array}{c}13.289 \\
(10.925-45.140)\end{array}$ & $\begin{array}{c}0- \\
3.647 .467\end{array}$ \\
\hline \multirow{5}{*}{$\begin{array}{l}\text { Mỗi đợt } \\
\text { nhâap } \\
\text { viện }\end{array}$} & CP ăn uống & $\begin{array}{c}308.571 \\
(87.873-529.269)\end{array}$ & 45,94 & $\begin{array}{c}0 \\
(0-480.000)\end{array}$ & $\begin{array}{c}0- \\
2.100 .000 \\
\end{array}$ \\
\hline & $\begin{array}{l}\text { CP vâân } \\
\text { chuyển }\end{array}$ & $\begin{array}{c}20.303 \\
(11.750-28.855) \\
\end{array}$ & 3,02 & $\begin{array}{c}12.467 \\
(11.645-23.158) \\
\end{array}$ & $0-60.000$ \\
\hline & CP ở trọ & 0 & 0 & 0 & 0 \\
\hline & CP khác & $\begin{array}{c}342.857 \\
(157.561-843.275)\end{array}$ & 51,04 & 0 & $\begin{array}{c}0- \\
4.200 .000 \\
\end{array}$ \\
\hline & $\begin{array}{c}\text { Tống CP TT } \\
\text { NYT }\end{array}$ & $\begin{array}{c}671.732 \\
(169.783-1.173 .680)\end{array}$ & 100 & $\begin{array}{c}410.000 \\
(22.336-553.290)\end{array}$ & $\begin{array}{c}0- \\
4.212 .467\end{array}$ \\
\hline \multicolumn{2}{|c|}{$\begin{array}{c}\text { Chi phí TT NYT cho năm } \\
\text { đầu tiên điều trị HPQ }\end{array}$} & \multicolumn{2}{|c|}{$\begin{array}{c}1.543 .273 \\
(1.401 .755-1.694 .791)\end{array}$} & $\begin{array}{c}1.310 .848 \\
(655.424-2.130 .128)\end{array}$ & $\begin{array}{c}0- \\
4.424 .112\end{array}$ \\
\hline \multicolumn{2}{|c|}{$\begin{array}{l}\text { Chi phí TT NYT cho năm } \\
\text { thứ hai điêu trị HPQ }\end{array}$} & \multicolumn{2}{|c|}{$\begin{array}{c}957.138 \\
(832.117-1.082 .158)\end{array}$} & $\begin{array}{c}655.424 \\
(163.856-1.474 .704)\end{array}$ & $\begin{array}{c}0- \\
4.456 .728\end{array}$ \\
\hline
\end{tabular}

Ghi chú: CP - chi phí, HPQ - hen phế quản, TT NYT - trực tiếp ngoài y tế, KTC - khoảng tin cậy, KTPV - khoảng tứ phân vị

Theo bảng 3, chi phí TT NYT cho mỗi đợt nhập viện có giá trị trung bình 671.732 VNĐ (95\% KTंC: 169.783 - 1.173.680 VNĐ) và gấp 4 lần so với CP TT NYT cho mỗi lần khám ngoại trú (163.856 VND; 95\% KTC: 81.943 - 245.768 VNĐ). Về cấu trúc $\mathrm{CP}$, đối với mỗi đợt nhập viện $\mathrm{CP}$ ăn uống chiếm tỳ lệ thấp nhất $(2,69 \%)$ và $\mathrm{CP}$ khác (sữa hay thực phẩm chức năng để hỗ trợ điều trị) chiếm tỷ lệ cao nhất $(86,12 \%)$. Đối với mỗi lần khám ngoại trú, CP khác chiếm 51,04\% và không khác biệt đáng kể so với chi phí ăn uống $(45,94 \%)$. Điều này có thể được giải thích bởi việc nằm viện của NB kéo theo sự gia tăng của CP ăn uống cho người bệnh và người thân trong thời gian nằm viện.

So sánh CP TT NYT ở 2 năm điều trị, đề tài ghi nhận $\mathrm{CP}$ này thấp hơn ở năm thứ 2 so với năm thứ 1 (957.138 VNĐ; 95\% KTC: 832.117 1.082.158 VNĐ so với 1.543.273 VNĐ; 95\% KTC: 1.401.755 - 1.694.791 VND; tương ứng).

Chi phí gián tiếp. Phỏng vấn mâuu nghiên cứu gồm 159 NB tại bệnh viện Quận 11 từ tháng 02/2021 đến tháng 05/2021, nghiên cứu ghi nhận chi phí gián tiếp (CPGT) của NB được đánh giá dựa trên thu nhập mất đi của người bệnh và người thân cho việc điều trị $\mathrm{HPQ}$ với kết quả được trình bày kết quả tại Bảng 4.

\section{Bảng 4. Chi phí gián tiếp của mối người HPQ (đớn vị tính: VNĐ)}




\begin{tabular}{|c|c|c|c|c|c|}
\hline \multicolumn{2}{|c|}{ Nội dung } & $\begin{array}{l}\text { Trung bình } \\
\text { (95\% KTC) }\end{array}$ & Tỷ lệ \% & Trung vị (KTPV) & Min - max \\
\hline \multirow{3}{*}{$\begin{array}{l}\text { Mỗi đợt } \\
\text { khám } \\
\text { ngoại trú }\end{array}$} & $\begin{array}{c}\text { Thu nhập mất đi } \\
\text { của NB }\end{array}$ & $\begin{array}{c}68.068 \\
(46.878-89.257)\end{array}$ & 78,7 & $\begin{array}{c}43.333 \\
(16.666-83.333)\end{array}$ & $0-1.333 .333$ \\
\hline & $\begin{array}{l}\text { Thu nhâap mất đi } \\
\text { của người thân }\end{array}$ & $\begin{array}{c}18.418 \\
(10.333-26.502)\end{array}$ & 21,3 & 2 & $0-300.000$ \\
\hline & Tổng CPGT & $\begin{array}{c}86.486 \\
(64.558-108.412)\end{array}$ & 100 & $\begin{array}{c}541.667 \\
(20.000-100.000)\end{array}$ & $0-1.333 .333$ \\
\hline \multirow{3}{*}{$\begin{array}{l}\text { Mỗi đợt } \\
\text { nằm viện }\end{array}$} & $\begin{array}{c}\text { Thu nhâpp mất đi } \\
\text { của NB }\end{array}$ & $\begin{array}{c}845.556 \\
(408.724-1.282 .386)\end{array}$ & 33,3 & $\begin{array}{c}606.666 \\
(166.667-933.333)\end{array}$ & $0-3.333 .333$ \\
\hline & $\begin{array}{l}\text { Thu nhâap mất đi } \\
\text { của người thân }\end{array}$ & $\begin{array}{c}1.540 .476 \\
(530.040-2.550 .912)\end{array}$ & 66,67 & $\begin{array}{c}800.000 \\
(0-1.866 .667)\end{array}$ & $0-9.333 .333$ \\
\hline & Tổng CPGT & $\begin{array}{c}2.386 .032 \\
(1.148 .249-3.623 .813)\end{array}$ & 100 & $\begin{array}{c}2.100 .000 \\
(840.000-2.800 .000)\end{array}$ & $\begin{array}{c}0- \\
12.666 .667\end{array}$ \\
\hline \multicolumn{2}{|c|}{$\begin{array}{c}\text { CPGT cho năm đầu tiên điêu } \\
\text { trị HPQ }\end{array}$} & $\begin{array}{c}1.086 .014 \\
(941.493-1.230 .534) \\
\end{array}$ & & $\begin{array}{c}778.374 \\
(345.944-1.383 .776)\end{array}$ & $0-7.590 .526$ \\
\hline \multicolumn{2}{|c|}{$\begin{array}{l}\text { CPGT cho năm thứ hai điêu } \\
\text { trị } \mathrm{HPQ}\end{array}$} & $\begin{array}{c}697.834 \\
(563.774-831.894)\end{array}$ & & $\begin{array}{c}345.944 \\
(86.486-778.374)\end{array}$ & $0-6.415 .298$ \\
\hline
\end{tabular}

Ghi chú: CPGT - chi phí gián tiếp, HPQ - hen phế quản, KTC - khoảng tin cậy, KTPV - khoảng tứ phân vị, NB - người bệnh.

Theo bảng 4, CP GT cho mỗi đợt nhập viện có giá trị trung bình 2.386.032 VNĐ (95\% KTC: 1.148.249 - 3.623.813 VNĐ), cao gấp 27,58 lần so với $\mathrm{CP}$ GT cho mỗi đợt khám ngoại trú (86.486 VND; 95\% KTC: 64.558 - 108.412 VNĐ). Về cấu trúc $\mathrm{CP}$, đối với mỗi lượt khám ngoại trú thu nhập mất đi từ người bệnh chiếm ưu thế $(78,7 \%)$ và gấp 3,69 lần so với thu nhập mất đi từ người thân dẫn người bệnh đi khám.

Ngược lại đối với mối lần nhập viện, thu nhập mất đi từ người thân do phải nghỉ việc để chăm sóc NB chiếm tới $66,67 \%$ gấp đôi khoản thu nhập bị mất từ NB nghỉ việc nằm viện. So sánh CP GT giữa 2 năm, nghiên cứu ghi nhận CP GT trung bình của NB HPQ thấp hơn ở nằm thứ 2 điều trị so với năm thứ nhất (1.086.014 VNĐ; 95\% KTC: 941.493 - 1.230 .534 VND so với 697.834 VNĐ; 95\% KTC: $563.774-831.894 \mathrm{VND).}$

Tổng chi phí điêu trị HPQ. Tổng kết tổng chi phí điều trị HPQ trong 2 năm điêu trị, đề tài ghi nhận kết quả và trình bày trong bảng 5 .

Bảng 5. Chi phí điều trị HPQ cho mỗi người bệnh qua hai năm tại bệnh viện Quận 11

\begin{tabular}{|c|c|c|c|c|}
\hline \multirow{2}{*}{ Chi phí/NB } & \multicolumn{2}{|c|}{ Năm thứ nhất } & \multicolumn{2}{c|}{ Năm thứ haí } \\
\cline { 2 - 5 } & $\begin{array}{c}\text { Chi phí trung bình } \\
\text { (95\% KTC) }\end{array}$ & Tỷ lệ \% & $\begin{array}{c}\text { Chi phí trung bình } \\
\text { (95\% KTC) }\end{array}$ & Tỷ lệ \% \\
\hline CP trực tiếp y tế & $\begin{array}{c}5.436 .764 \\
(4.928 .144-5.945 .384)\end{array}$ & 67,41 & $\begin{array}{c}4.669 .945 \\
(4.180 .437-5.159 .452)\end{array}$ & 73,84 \\
\hline CP trực tiếp ngoài y tế & $\begin{array}{c}1.543 .273 \\
(1.401 .755-1.694 .791)\end{array}$ & 19,13 & $\begin{array}{c}957.138 \\
(832.117-1.082 .158)\end{array}$ & 15,13 \\
\hline CP gián tiếp & $\begin{array}{c}1.086 .014 \\
(941.493-1.230 .534)\end{array}$ & 13,46 & $\begin{array}{c}697.834 \\
(563.774-831.894)\end{array}$ & 11,03 \\
\hline Tổng CP điều trị & $\begin{array}{c}8.066 .051 \\
(7.338 .823-8.793 .279)\end{array}$ & 100 & $\begin{array}{c}6.324 .916 \\
(7.338 .823-8.793 .279)\end{array}$ & 100 \\
\hline P value & \multicolumn{4}{|c|}{$<0,05$} \\
\hline
\end{tabular}

Ghi chú: CP - chi phí, KTC - khoảng tin cậy, KTPV - khoảng tứ phân vị, NB - người bệnh.

Theo bảng 5 , đề tài ghi nhận tổng $\mathrm{CP}$ điều trị $\mathrm{HPQ}$ năm đâuu tiên cao hợn năm thứ hai (8.066.051 VND; 95\% KTC: 7.338.823 8.793.279 VNĐ so với 6.324.916 VND; 95\% KTC: 5.638.181 - 7.011.651 VND; tương ứng). Sự khác biệt này có ý nghĩa thống kê với $p<0,05$. Cấu trúc $\mathrm{CP}$ điều trị tương đồng ở cả 2 năm với CP thuốc chiếm ưu thế $(67,41-73,84 \%)$; tiếp theo CP TT NYT $(15,13-19,13 \%)$ và thấp nhất là CP GT $(11,03-13,46 \%)$. Nhìn chung tất cả các chi phí đều giảm dần qua hai năm NB tham gia chương trình QLHNT tại bệnh viện Quận 11.

\section{BÀN LUÂ̂N}

Nghiên cứu đánh giá $\mathrm{CP}$ điều trị $\mathrm{HPQ}$ của mẫu gồm 232 NB tham gia chương trình QLHNT thăm khám điều trị hai năm liên tục tại bệnh viện Quận 11 trong giai đoạn 2017 - 2020. Kết quả ghi nhận tổng $\mathrm{CP}$ cùng với 3 cấu phần $\mathrm{CP}$ TTYT, TT NYT và GT đều giảm có ý nghĩa thống kê ở 
năm điều trị thứ hai so với thứ nhất. Điều đó cho thây ý nghĩa của chương trình QLHNT trong việc giảm thiểu $\mathrm{CP}$ điều trị cho người bênh xét ở cả $\mathrm{CP}$ trực tiếp y tế hay ở $\mathrm{CP}$ tiền túi của người bệnh ( $C P$ TT NYT và $C P \mathrm{GT}$ ). Điều này có thể được giải thích bởi chương trình QLHNT giúp nâng cao hiệu quả điều trị, giảm thiểu số đợt nhập viện nội trú và giảm thiểu diễn tiến nặng hơn của bênh.

Ngoài ra, nghiên cứu ghi nhận CP TTYT trong điều trị HPQ chiếm tỷ lệ cao nhất với 67,41 $73,84 \%$ tổng $\mathrm{CP}$ điều trị. Kết quả này tương đồng với nghiên cứu của Miriam năm 2003 tai Mỹ, trong đó $\mathrm{CP}$ bình quân hàng năm cho mỗi NB HPQ gồm $65 \% \mathrm{CP}$ trực tiếp và $35 \% \mathrm{CP}$ GT [8]. Như vậy, có thể thấy CP TT YT là gánh nặng kinh tế lớn trong điều trị $\mathrm{HPQ}$, vì vậy việc giảm thiểu gánh nặng kinh tế của bệnh cần cẩn nhắc giảm thiểu các cấu phần CP TTYT.

Đây là nghiên cứu đầu tiên tại bệnh viện quận 11 đánh giá lợi ích của chương trình QLHNT trong điều trị HPQ ở khía cạnh CP điều trị. Nghiên cứu đã đánh giá toàn diện $\mathrm{CP}$ điều trị $\mathrm{HPQ}$ theo quan điểm của người chi trả và theo dõi quần thể NB HPQ tham gia chương trình QLHPQ trong hai năm liên tục. Tuy nhiên nghiên cứu còn tồn tại một số hạn chế. Với tình hình dịch bệnh COVID-19 ảnh hưởng đến tình hình khám chữa bệnh nói chung và tại bệnh viện quận 11 nói riêng trong năm 2020, nghiên cứu đã không bao gồm dữ liệu NB HPQ năm 2020. Ngoài ra, nghiên cứu mới chỉ dừng lại ở việc khảo sát $\mathrm{CP}$ điều trị $\mathrm{HPQ}$ qua 2 năm NB tham gia chương trình QLHNT và chưa đánh giá được toàn diện tính chi phí - hiệu quả của chương trình QLHNT.

\section{KẾT LUÂN}

Chương trình quản lý hen ngoai trú tại bênh viện Quận 11 giúp giảm tổng $C P$ điều trị của người bệnh $\mathrm{HPQ}$ sau 2 năm tham gia điều trị. Cân tiếp tục triển khai chương trình và đánh giá tính chi phí - hiệu quả của chương trình trên nhiều quan điểm khác nhau trong tương lai.

\section{TÀI LIẸU THAM KHẢO}

1. https://www.who.int/vietnam/vi/news/featu re-stories/detail/ten-threats-to-global-health-in2019 truy cập 01/10/2021

2. Global initiative for asthma (GINA) (2015) Definitison, description and diagnosis of asthma, Global strategy for asthma management and prevention.

3. Sauni Riitta, Panu Oksa (2003), Increased risk of asthma among Finnish construction workers, Occupational Medecine 53(8), 527-531.

4. S.K. Chhabra (2007), Assessment of Control in Asthma: Current Scenario and Instruments for Measurement, Indian J Chest Dis Allied Sci 2007; 49: 5-7

5. Võ Thi Rĩ, Pham Anh Tuấn (2018), Tình hình bệnh tật và hiệu quả quản lý bệnh nhân hen/ COPD đến khám tại phòng khám hổ hấp bệnh viện Quận 11, Hội nghị Khoa học kỹ thuật lần I - Bệnh viện Quận 11, trang 45 - 50.

6. Nguyến Thanh Bình (2020), Dịch tễ dược học, Nhà xữát bản $Y$ học.

7. Nguyễn Thi Thu Thủy (2020), Kinh tế dược trong thực hành lâm sàng, nhà xuất bản Đại học quốc gia Tp. Hồ Chí Minh.

8. Cisternas MG, Blanc PD, Yen IH, Katz PP Earnest G, Eisner MD, Shiboski S, Yelin EH. A comprehensive study of the direct and indirect costs of adult asthma. J Allergy Clin Immunol. 2003 Jun;111(6):1212-8.

\section{KẾT QUẢ SớM PHẪU THUÂTT KHÂU THÌ ĐẦU ĐIỀU TRI THỦNG THỰC QUẢN}

Lý Minh Tùng*, Lê Quang Nghĩa*, Trần Văn Minh Tuấn*, Trần Hữu Duy*

\section{TÓM TẮT}

Đắt vấn đê: Thủng thực quản là một cấp cứu ngoại khoa hiếm gặp có tỉ lệ biến chứng và tử vong cao. Lựa chọn phương pháp điều trị tốt nhất cho bệnh nhân còn nhiều tranh luân. Hiên nay, khâu thì đâu dần được xem là một phương pháp điêu trị hợp lý do tỉ lệ

*Đai hoc Quốc Gia TP. Hồ Chí Minh

Chịu trách nhiệm chính: Lý Minh Tùng

Email: Imtung@medvnu.edu.vn

Ngày nhận bài: 7.9.2021

Ngày phản biên khoa hoc: 28.10.2021

Ngày duyệt bài: 10.11.2021 thành công cao, ngay cả trong những trường hợp thủng thực quản đến trễ. Nghiên cứu này nhằm đánh giá kết quả sớm của điều trị khâu thì đầu trong thủng thực quản trong 5 năm gần đây tai bênh viện Bình Dân. Phương pháp nghiên cứu: Mô tả hàng loạt ca thủng thươ quản được điều trị khâu thức quản thì đầu tại bệnh viện Bình Dân trong khoảng thời gian 5 năm từ 2015 đển 2020. Kết quả: Có 24 bệnh nhân được khâu thực quản thì đầu, gôm 10 ca thủng thực quản ở cổ (42\%), 10 ca ở ngực (42\%) và 4 ca ở bụng (16\%). Khâu thì đâu có tỉ lệ thành công chung là $88 \%$. Tỉ lệ rò miệng khâu là 8 ca (33\%), trong đó phải mổ lại 3 ca $(12 \%)$. Không có ca nào tử vong. Kết luận: Chẩn đoán thủng thực quản còn nhiều thách thức, cần chẩn 